I now commenced with the hydriodate of potass, a remedy well known to possess great power over the heart and secreting organs generally, and thereby admirably calculated to fulfil the object $I$ had in view, viz., to control the heart's action, and produce diuretic effects. The plan of treatment was unfortunately not strictly adhered to by the patient, and when he next visited me, having allowed ten days to elapse, he was much worse; whereupon I urged him to get into an hospital, in the meanwhile providing hin with more hydriodate, in increased doses, with the addition of tincture of digitalis and aperients.

Such is the history of this case, and the treatment $I$ adopted, the propriety of which I challenge the anonymous writer to question, selecting for judges your experienced and intelligent readers.

If the anonymous writer has anything new to add, I shall be only too happy to be informed, and beg to assure him I shall be the last person to shrink from the investigation. As to the Latin errors, they are so evidently the combined result of an illegible hand and hurry arising from the immense number of patients $I$ have to prescribe for at the dispen. sary, three days in the week, that they are scarcely worth criticism; but it is enough that the dispenser of the institution understood the prescriptions: had they been intended for publication it would have been another matter. I am, Sir, your obedient servant,

14, Albemarle-street,

$$
\text { John Hastings, M.D. }
$$

Dec. 6, 1842.

\section{Post-mortem Examination.}

The examination of the body was made five days after death. It was naturally considerably decomposed, and presented extensive separation of the cuticle. There was no emaciation, or only very little.

In the cavity of the peritoneum were found about two pints of bloody serum.

The Stomach was natural in size, and healthy throughout its whole extent, excepting at about the middle of the lesser curvature, where there was considerable thickening; and an ulcerated opening, apparently leading to an abscess in the liver, which contained about an ounce of darkish-green fluid, having no peculiar smell or appearance.

The Intestines were healthy, and contained a small quantity of a similar fluid.

The Liver. - Old and firm bands of adhesion were found, connecting this organ to the under part of the diaphragm and posterior part of abdominal muscles. It was enormously enlarged, and weighed nine pounds, filling the whole of the right side, and the upper and anterior part of the abdomen. It presented large masses of cancerous deposit, many being in a softened condition. One of these opened into the stomach.
The Gall.bladder was small, and contained some biliary calculi.

The Spleen was large, and, as well as the pancreas and the kidneys, was healthy.

The Heart was flabby, and the cavities were large, and the walls consequently thin.

The Lungs.-The right was gorged with black fluid blood, the result of transudation. Firm bands of adhesion connected the whole of the right lung to the side of the chest. The left lung was healthy. About a pint and a half of fluid was found in the pleura.

The Brain and its membranes were perfectly healthy.

Where one such tale as this comes to light, how many thousands of dispensary patients die and leave no sign ?

** The reader will be at a loss now to discover in what respect the publication of the prescriptions last week was either " malicious or very contemptible." They were inserted in perfect ignorance even of the name of the medical officer who ordered the medicine, although that of Dr. Hastings was printed on the dispensary ticket. As for the "Latin errors" they formed no part of the question at issue, as Dr. Hastings will plainly see on perusing the account of the autopsy, which was promised last week to be given to-day. As a specimen of dispensary practice-a species of practice which does not even afford leeches in the medical treatment of patients, however urgently indicated-we agree with Dr. Hastings that the case may safely be left to the experienced and intelligent readers of this journal for a judgment upon the facts.

\section{TINCTURE OF IODINE FOR THE} LIDS IN CONJUNCTIVITIS.

To the Editor.-Sir: I find in THE LANCET of Nov. 19th, a strong recommendation from Dr. Hocken, of the nitrate of silver in conjunctivitis, the mode of applying it being to smear it over the upper palpebræ; and in the number for Nov. 26, a reclamation of the practice by $\mathbf{M r}$. Wormald.

Having been for many years in the habit of prescribing for cases of conjunctivitis (chiefly strumous, and therefore the most obstinate, usually), and having enjoyed many opportunities of watching these distressing cases amongst the numerous out-patients of the infirmary at this place, I would beg to recommend to Dr. Hocken a trial of painting the palpebræ of the affected eye, or eyes, with the alcoholic solution of iodine, commonly called the tr. iodin. For very fine skin in children the strength may be low. ered. I was led to apply this remedy thus ; by reflecting on the continuity of surface 
between the skin and the conjunctiva ; and, truly, the effect has been beneficial in an extreme degree. The distressing lachrymation is immediately relieved, and I have had reason to think that in several cases $I$ have stopped ulceration of the comea. The remedy is easily applied; it dries on, gives no trouble, and requires some two or three applications every week, according to the effects. In the first stage leeches have almost always been premised, but most of the cases have been brought before me in a very advanced and intractable state, when no leeches were requisite. If Dr. Hocken and Mr. Wormald have not tried this application in the way I have described, I think they will find it an useful addition to their present list. I am, Sir, yours obediently,

\section{J. J. FuRNIVALL, M.D.,}

Physician to the General Infirmary at Hertford.

Hertford, Nov, 27, 1812.

\section{FOREIGN MEDICAL CERTIFICATES.}

To the Editor.-Sir: In your valuable periodical of the $26 \mathrm{th}$ November, I noticed in your answer to " R. G." an error, which I can from personal experience correct. You were right respecting the College, but certificates of attendance at lectures and hospital practice in Paris are recognised by the Hall, and there is an article to that effect in their printed regulations. The College of Surgeons, however, with that illiberality which characterises nearly all their proceed. ings, will not receive any such certificates. Although those lecturers and hospitals are second to none in Europe, yet they reject the certificates of such men as Orfila, Velpeau, Andral, and Cloquet, and snatch at the testimonials of obscure lecturers in fourth-rate London schools, whose names have never been heard of or printed beyond their classrooms or placards. Many of the examiners themselves receiving heavy fees from the students for certiticates, their reasons for excluding foreign certificates is obvious enough. The Faculty of Medicine of Paris admits candidates holding the diploma of the College of Surgeons to the examination for the degree of M.D., on producing also certificates of attendance to the extent of onethird of the Paris curriculum, the diploma of the London College being reckoned for the remainder. Unhappily, that College is a stain upon the medical laws of the country soon it is to be hoped to be deprived of the unnatural and injurious influence which it is enabled to exercise upou medical education. I am, Sir, yours respectfully,

J. Berncastle, M.R.C.S., L.A.C., \&c. London, Nov, 29, 1842.
The Function of the Spleen,-In our notice of Mr. Stevens's reported discovery of the function of the spleen, we deduced that fat was disease, a result which, we presume, according to the views of Mr.S., may be worked out thus :-The chief element of fat is carbon. The liver eliminates, or uses, carbon in the secretion of bile. Stout people are all commonly presumed to have small spleens, et vice versâ, as well as a sluggish secretion of bile, and a consequent retention of carbon in the form of fat. The connection is easily traced. With regard to another branch of this subject, some physiologists have persuaded the better-informed graziers that the quantity of real muscular tissue is, in the same adult animal, nearly always the same, and that a lean animal differs only from itself in a wellfed state, as regards the quantity of fat (and carbon). By the experiments of Mr. Stevens we take it for granted that that gentleman is inclined to this latter opinion, the fat intermingling with the muscular fbrillæ, and permeating the whole cellular tissue, not perhaps even excepting the sarcolemma, the hint being given to the sheep-graziers as a fact that probably possesses a certain value beyond that which attaches to it as a mere physiological curiosity, and as a datum in Mr. S.'s conclusions on deeper physiological points.

\section{THE SINE-SPLENIC MODE OF FATTENING.}

To the Editor.-Sir: In my paper "On Some Effects of Tying the Splenic Artery," which appeared in THE LANCET of Oct. 8th, the remarkable fattening of animals after that operation is clearly shown; and in a following paper, forwarded to THE LANCET on October 22nd, the proposition of applying that operation to the specific purpose of fattening animals, is clearly announced as a necessary result of my experiments. It is but fair, then, that you give me the opportunity of stating that my paper containing this proposition has been at your office six weeks; and it is notorions with my friends, amongst whom I may name Mr. Bishop, surgeon, of Newington, and $\mathrm{Mr}$. Gane, of the same place, that $I$ adopted this plan some months since. The former gentleman is, indeed, aware of an offer made to me of a smart sum of money by a dealer in Leadenhall-market if I would tell him my method of fattening animals; and presently we shall see that cachexy, or disease of the assimilating powers, which is the "law" or "nature" of phthisis (by which I mean that 